\title{
Utilizing Reflective Practice to Develop Agency in Goal Setting and Achieve- ment in Workplace Learning Environments
}

Dr. Andrea Goncher, Charles Sturt University

Andrea Goncher is a lecturer in Civil System Engineering at Charles Sturt University in Bathurst, Australia. Her research interests include text analytics, international higher education, and engineering design education. 


\section{Utilizing Reflective Practice to Develop Agency in Goal Setting and Achievement in Workplace Learning Environments}

\section{Introduction}

Misalignment with university and industry can present challenges to the professional formation of engineers within the profession [1]. Integrating workplace learning experiences throughout university study, and working with industries can help students meet the requirements of accreditation bodies, and develop their professional identity [2].

Reflective practice contributes to preparing graduates to be employable as their graduate learning outcomes relate to life-long learning. Reflective practice can include the application of skills in work contexts, as well as reflecting on the experiences to advance learning. Reflective practice is an essential attribute for engineers due to it's ability to promote thoughtfulness [2] and can support engineers in learning from previous experiences and improving future experiences.

Activities grounded in reflective practice allow students to actively engage in identifying and developing the goals that they would like to achieve during their first placements. Utilizing reflective practice as part of their early workplace learning experiences can facilitate students in developing professionalism and their professional identity [1]. Integrating reflective practice and goal development, as it relates to professional practice can help to prepare graduates to effectively enter their community of practice, where engineering is a rapidly changing form of work [3].

To help minimize the gap between university and work, with respect to engineering practice [4], we focus on integrating student workplace learning experiences and reflective goal setting practices. This paper presents a case study of engineering students currently in workplace learning environments. Students participated in a parallel reflective planning and review-focused course designed to help students to structure setting goals and objectives, as well as reflect on workplace practices. The purpose of this study was to investigate, what is the impact of reflective practice on student goal achievement in workplace learning experiences?

\section{Theoretical Framework}

Workplace learning (WPL) is part of the education for practice spectrum, and is supported by unique teaching strategies and appropriate supervision at Charles Sturt University's (CSU) Engineering program. The objective of the WPL experiences are to utilize unique teaching strategies and learning designed to help develop desirable and work-ready graduates. The design of WPL experiences is based on educational theory and pedagogical considerations. Reflective practice [5] contributes to preparing graduate to be employable as it relates to lifelong learning. WPL is not only about applying skills in work contexts, but reflecting on the experiences to advance learning. 
Potential benefits of WPL are based on constructivist learning theory [6;7], which provide the learner with activities to construct their own knowledge. The WPL environments can act as communities of practice [8] where learners construct knowledge from each other. WPL experiences take into account the situated nature of cognition, e.g. the intersection of learning and working, to develop professionalism and professional identity [1].

\section{Context: Industry Collaboration and Student Learning}

A core element of the CSU Engineering program education is embedding students in industry while they learn from, and engage with, the profession. As part of the CSU Engineering degree, students undertake four, one-year, paid work placements with industry partners in a range of engineering organizations, e.g. local government, consulting firms, international organizations, while continuing to learn theoretical content through an online interface. Figure 1 illustrates two examples of students on site for their workplace learning duties. CSU Engineering's first intake of students commenced their placements in July 2017, after 18 months of project-based and self-directed online learning.
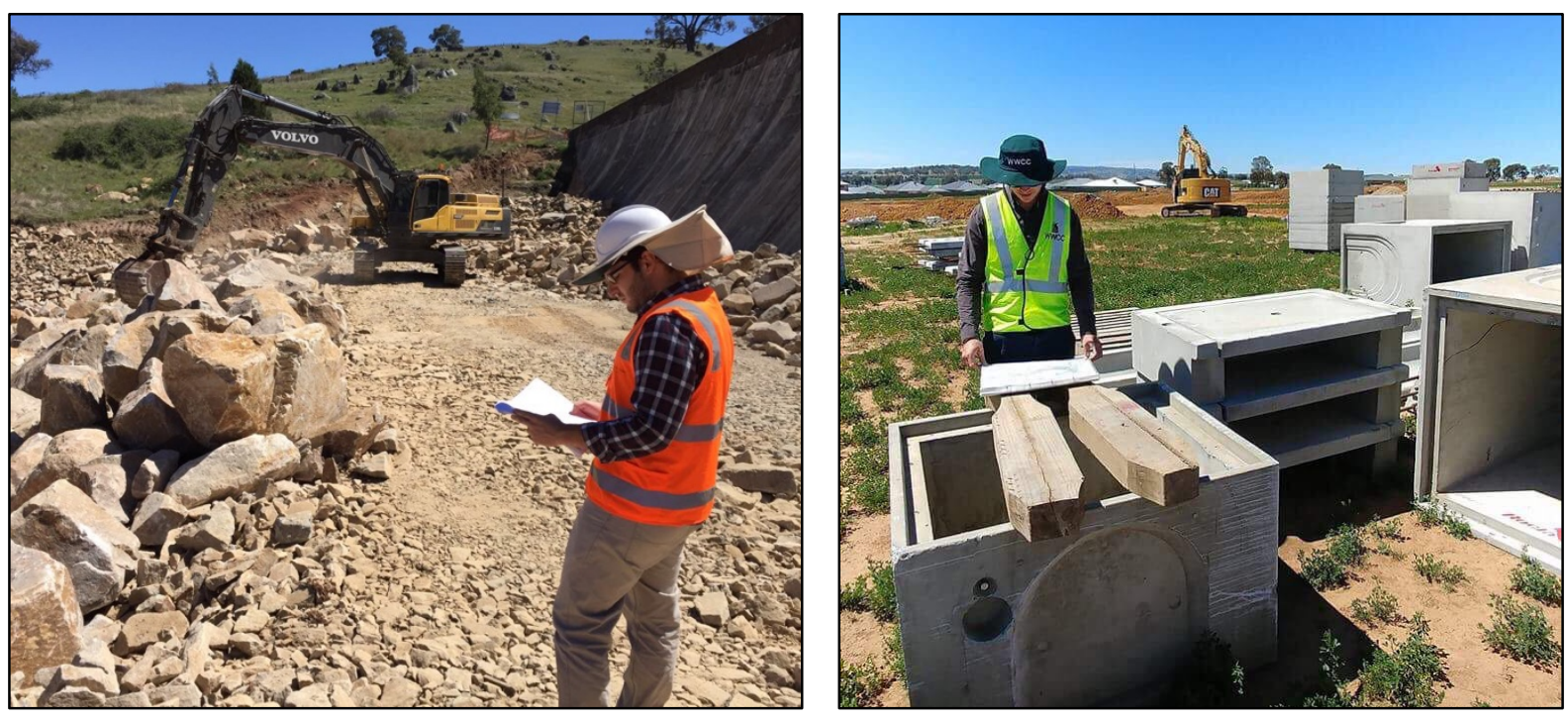

Figure 1. Engineering students on industry placements

Seventeen students enrolled in workplace learning placements and the planning and reviewfocused class. Students on placement worked with 15 host organizations, where the organizations exist at the local, national, and international levels. Students were involved in various projects across the civil engineering discipline. Example projects that students worked on included a pedestrian and cyclist river bridge, dam safety upgrade, commercial building upgrade, local effluent disposal investigations, and road and roundabout design. Local government organizations hosted the majority of placements; other students were distributed across both public and private organizations. Table 1 details the host organization categories. 
Table 1. Distribution of engineering students in various industry categories

\begin{tabular}{|c|l|r|r|}
\cline { 2 - 4 } \multicolumn{1}{c|}{} & \multicolumn{1}{c|}{ Host Organization } & Number of Students & \multicolumn{1}{c|}{ Percent } \\
\hline \multirow{3}{*}{ Public } & Local Government & 7 & $41 \%$ \\
\cline { 2 - 4 } & Public Works & 2 & $12 \%$ \\
\hline \multirow{3}{*}{ Private } & International Private & 1 & $6 \%$ \\
\cline { 2 - 4 } & National Private & 2 & $12 \%$ \\
\cline { 2 - 4 } & Local Private & 4 & $29 \%$ \\
\hline
\end{tabular}

\section{Resources Learning Outcomes Assessment}

Prior to beginning their industry placements, students completed three semesters of a combination of face-to-face and online learning courses. One of the required face-to-face performance, planning, and review (PPR) courses was designed to help students prepare for their industry placements and WPL environments by having students develop and achieve identified (academic) goals. Based on students' successful completion of this course, we expect students to be able to develop S.M.A.R.T (Specific, Measurable, Attainable, Relevant, and Time-specific) goals for their own learning. The main objective of these learning activities is to help students manage the transition from university to the upcoming work placement.

Once students commence industry placements, the program structure requires them to set relevant WPL and academic goals that align with the timing of their placements. The workbook was an online resource created for students to self-assess their goal setting abilities, and to progress towards goal completion for their placements. The author designed the resource to help students anticipate workplace situations, identify goals, and meeting the learning objectives for the PPR course. The main sections that prompt students to reflect on previous and future themes include, Identification of Goals, Previous Work or Job Experience, and Revised Identification of Goals. An excerpt from the introduction to the workbook is illustrated in Figure 2.

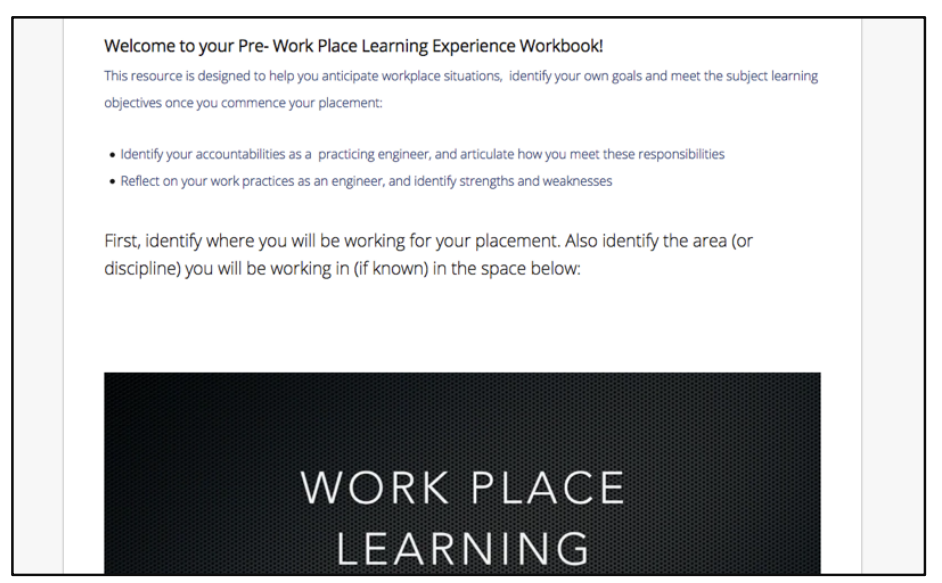

Figure 2. WPL student workbook introduction

Goal identification, as a workplace preparation activity, is a beneficial learning activity because of the nature of reflection. A self-paced assessment resource, which addresses a 
student's goal identification, is important for preparing students for their early career placements [9]. Students should be able to engage with a WPL resource at their own rate, and have time to think about their goals, and the experiences that will allow them to achieve those goals, in order to prepare for placement.

The online workbook format enables students to actively engage in identifying and developing the goals that they would like to achieve during their placements. The format provides several forms of question delivery and prompts for students to reflect on their goal setting approach. This early WPL resource encourages students' use of reflective practice that can help guide them to develop their goals. Reflecting on previous experiences - see example prompts in Figure 3- to inform their goal setting approach promotes the students' capacity to be thoughtful in what they want to achieve [10].

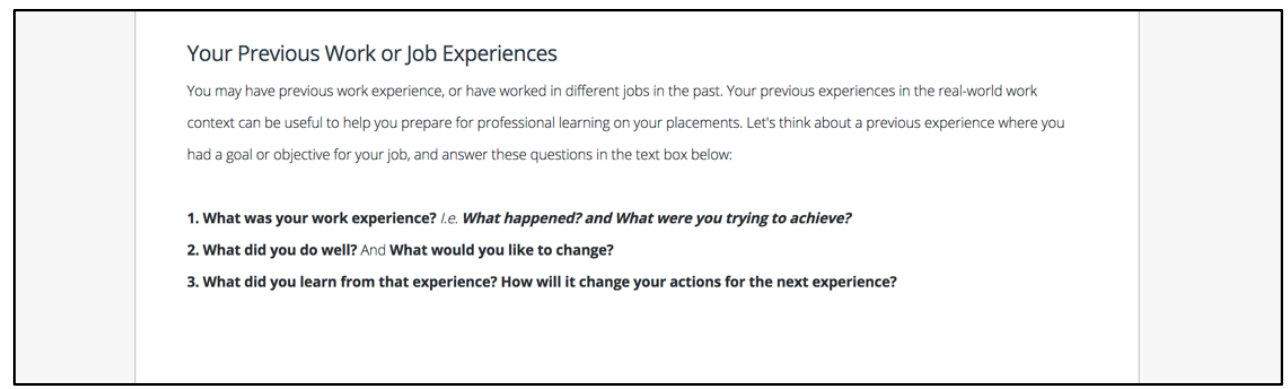

Figure 3. Example Workbook prompt to reflect on previous experiences

Actively engaging in reflective practice, e.g. by completing the workbook prompts, is not only important for the early WPL experiences, but also for students' future practice $[1 ; 11]$ The resource utilized in this study was designed to prepare students for reflective practice throughout their placements, so that critical reflection is not as challenging or uncomfortable having actively engaged in the early WPL activity. Part of critical reflection is engaging in self-assessment, so the resource prompts the student to identify "how will you determine if you have met this goal?", illustrated in Figure 4.

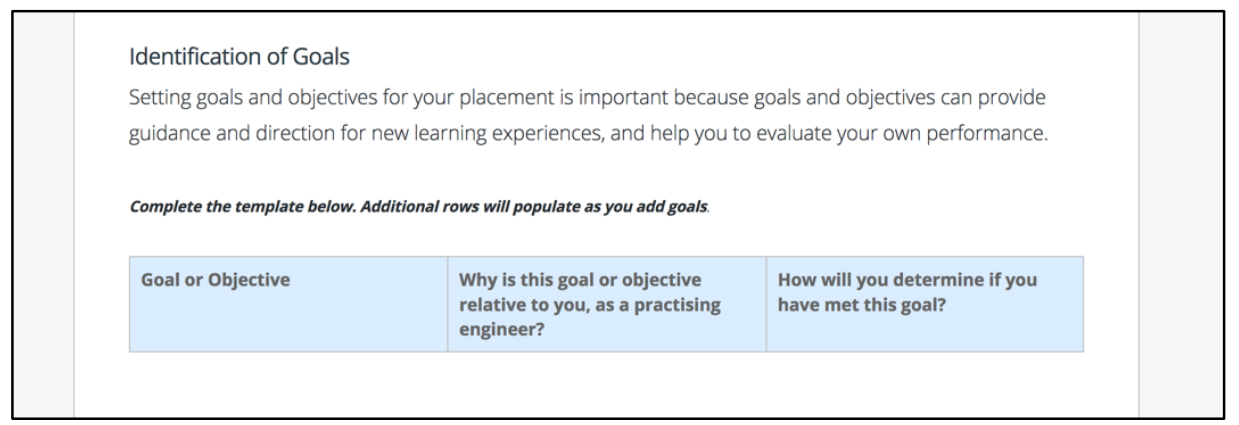

Figure 4. Three parts to identifying goals

Identifying the goal, its relevancy, and plans for evaluation allows the student to have agency in their own evaluation of performance, and their response will be used in the during- and post-placement evaluation of their goals. For example, throughout the WPL subject, the cadet engineer will evaluate whether they are achieving, or are on track to achieve their goals. In 
the post-WPL experience, they can reflect on "was this the most effective way to evaluate their achievements?", and what they would "improve for the next WPL subject", or goalsetting activity.

The objective of the resource described above was designed as a technique for learning outcomes assessment; the resource also elicits important information from students regarding the impact of reflection on goal achievement and workplace learning experiences. The following sections describe the research methods employed to examine these experiences.

\section{Research Methods}

\section{Sample}

The participants in this study were students enrolled in their second year, second semester of the engineering degree program at the time of the data collection. The student population from the WPL and parallel performance, planning, and review course included fifteen male students and two female students, all in civil engineering majors. We selected four total students for this study, which included three men and one women. Two of the participants, both male, had previously worked in a trade industry before entering the civil engineering degree program, and the other two entered the program directly after completing year 12 in high school. The selection of students for this study was representative of the total students' experience and sex. We did not take into consideration students' interests or personal habits during the participant selection stage, but these factors will be addressed in the limitations section.

\section{Data Collection:}

The two main forms of data collection were students' responses from the course documents and individual interviews with the participants conducted after the initial goal setting activities. The questions and responses extracted from the course documents, i.e. the students' reflections, included:

1. Identification of Goals

a. Goal or Objective

b. Why is this goal or objective relevant to you, as a practicing engineer?

c. How will you determine if you have met this goal?

2. Your Previous Work or Job Experiences

a. What was your work experience? I.e. What happened? and What were you trying to achieve?

b. What did you do well? And what would you like to change?

c. What did you learn from that experience? How will it change your actions for the next experience?

3. Revised Identification of Goals

a. Enter any revised, or additional goals that you would like to achieve on your work placements.

i. Goal or Objective

ii. Why is this goal or objective relevant to you as a practicing engineering? 
iii. How will you determine if you have met this goal?

We conducted 30 minute qualitative interviews with the four students currently on industry placements in public and private civil engineering organizations. The interviews took place approximately three to four months after students started their placements, and were conducted to inform the improved development of course teaching materials for a subsequent offering. Four questions were presented to each of the four participants:

1. Describe a brief overview of your placement and some of the projects you are working on.

2. What are/ were your goals for the placement?

3. What do you wish you had known prior to starting placement?

4. Any advice for engineering students about to go on placement.

Interview questions 1 and 2 were asked for the interviewer to gain context for each of the participants placements, as well as for the students to revisit or reflect on their answers provided at the start of their placements in the reflective document template.

Data Analysis:

We used document analysis [12] to analyze students' written reflections and documentation of their goals and progress toward their goals. This format provided several forms of question delivery, and prompts for students to reflect on their goal setting and achievement approach. The qualitative student interviewers were audio recorded and transcribed.

This study's analysis approach required that data be examined and interpreted to elicit meaning, gain insights, and develop an understanding of the representative student experiences. The author compiled and labeled the responses from the participants' documents and transcripts. Three rounds of coding were applied to extract themes from 1) document responses, 2) transcripts, and 3) mutual, or similar themes from both the document responses and the interview responses. In future work related to this study, the identified themes and resulting codes will be applied by additional coders to ensure the reliability of the coding scheme.

\section{Results}

Overview

Reflecting on previous experiences helped to inform their goal setting approach and promoted the students' capacity to be thoughtful in what and how they wanted to achieve their goals. Goal identification, as a workplace learning activity, was important to students' professional development, e.g. how they planned to progress and develop as an engineer in the given WPL context. Input from their industry supervisors helped students to create goals, and subsequently impact if they felt they could achieve these goals.

The learning activities, e.g. written reflections and prompts, were designed as self-paced resources for students to prepare for and engage in their placements. However, students had 
self-identified difficulties managing the reflective activity with their specific duties required by the host organizations.

Pairing reflective activity and the opportunity for agency in students' setting their workplace goals, resulted in the participating students' ability to realize their own capacity in achieving these goals, and capacity to develop as a practicing engineer.

Example data from identified themes:

Role of the Industry Supervisor and Academic Mentor

"I wanted to set achievable goals that fitted the workplace and allowed for a rounded learning experience. To make this possible I met with both my [university mentor] and [placement supervisor]. They enabled goals that suited the tasks that I will undertake at [industry host], whilst meeting the requirements of university. With both parties in agreeance, the process wasn't too difficult."

"In the future I will continue to seek guidance from other engineers when creating goals, as I respect that my colleagues have experienced conditions similar to these when they began working as an engineer."

"In future circumstances, I would like more time with my industry partner to further develop my industry goals. I think that [students] should be allowed three weeks [after the start of the placement] to finalize [their goals]"

Integrating reflective activity and industry placement duties

"Overall, I am currently finding managing work with university difficult, however the support I have received as of yet has been very helpful. The process of creating goals has been made easy by the people that I have interacted with."

"Through my part time work I can value the need to manage, plan and set goals. Creating agendas work-time-tables, and action plans, will help me remain on task for the remainder of the challenge. I believe that through my timely commitments to completing work, and through past experience, I will be able to complete the challenge at the expense of my personal life."

"I hope in the future that I will have more time to do university studies and on my [review of goals], perhaps change any goals as I develop and settle more into the workplace."

$\underline{\text { Recognized capacity to set and achieve goals }}$

"I learned that I am quite independent and capable of more than I think I am. Change is not something everyone can adapt to and I am certainly thankful I am surviving!"

"I feel that these goals will contribute greatly to my professional development, especially in providing a broad range of skills and competencies that I can work towards achieving. The wider my breadth of competency, the more rounded an engineer I shall be." 
"I feel much more confident and indeed relaxed in myself, than on previous occasions when starting a new position. I attribute that largely to having already worked, with previous engineering experience as both an electronics technician."

\section{Discussion}

Engaging with the reflective activities is beneficial for the students to have agency in setting their own goals. Workplace learning is not only about apply skills in work contexts, but reflecting on the experiences to advance learning. The resource was designed and structured to enable students to anticipate workplace experiences and be self-directed in identifying what they want to accomplish on their placements and how they will achieve this.

Integrating industry collaborations throughout an engineering education program and working with host organizations facilitates the development of student engineers and future professionals that industry needs. The industry partners have the opportunity to work with students, and build a community of practice with the students and professional engineers to help each other develop skills and offer new perspectives. Important outcomes of engagement with industry include the development of future professionals that meet industry's needs.

\section{Strengths and Limitations}

Self-paced and reflective activities, where students set their own goals and reflect on their experiences has strengths and limitations. The strengths are focused on students having agency to create and reflect on their own goals and achievements, however the resource is limited by the opportunity for input from the WPL educator, or host organization. The resource utilized and discussed in this paper could be improved by incorporating the WPL supervisor and/or host industry organization. Goal setting within the workplace should utilize the co-design of goals with the student and WPL educator. In a well-designed WPL experience, the WPL educator will have had training and/or communicated with the university regarding the skills needed for workplace learning [6] and can assist the engineering student to develop goals that help them to gain competence in those skills, e.g. communicating decision making, listening and questioning. One of the participants provides some guidance to help overcome this limitation when he describes his experience of setting goals. He suggests that the cadet engineers perform research on the company, so that the goals can be achieved within the capacity of the host organization. Prior research or awareness of the company's mission, objectives, projects, etc. can help students identify if their placement at the company will help to support achieving their identified goals. If the company and student's goals do not align, students would have the opportunity to reevaluate their interest in working for the company, or if their goals would align with the company at a more opportune time in their career.

Another limitation to this study was the sample used was based on the students who volunteered to participate in both the interviews and document use. While, the sample was representative of the number of male and female students on placement, and the level of previous work experience, it did not account for students' personal habits or interests. The author did not collect specific data for the interviewed students' backgrounds, interests, and 
personal habits, which has the potential to make the results potentially biased toward the type of students who participated in this study.

The students who volunteered to further discuss and reflect on their goals in the interview, may also have been more inclined to engage in reflective practice and feel comfortable with the process.

\section{Recommendations for WPL educators and supervisors}

Supervisors' typical expectations are to offer support and guidance, including regularly meeting with the student and helping the student to integrate and feel like part of the workplace $[13 ; 14]$. More experienced practitioners can provide direct guidance supports a greater effective integration into practice-based experiences [15].

Universities and workplaces need to carefully and continually develop their relationships, and understanding of each other's expectations. Host industry supervisors and WPL educators should also be prepared for the WPL experience [16]. Various factors can affect supervisory practices such as the WPL model, location of the supervisors and disciplinary traditions [10]. Because practices and policies are dependent on context, it is very important for supervisors, universities, and WPL stakeholders, to have a shared understanding for the implementation and execution of experience-based education models [13;15]. Other contextualized documentation related to the organization should also be considered and shared when considering the "Supporting Infrastructure" in the WPL implementation plan. Preparation should not be the responsibility of one person or organization if the collaboration aims to be mutually beneficial to the student, university, and workplace and provide experiences that will ultimately advance the profession.

First, I would recommend that the student, host, and university mentor or coordinator, depending on context, co-design appropriate learning activities that will also assist in the process of explicating expectations [10]. In the CSU Engineering placements, the academic mentor, and the host supervisor develop a learning agreement with the student to identify and agree on goals for the student's learning experience in the workplace as well as academic goals that can help to integrate theory and practice. Second, I would systematize communication to occur prior to the student commencing and during their placement [16]. Mentors and supervisors can help to familiarize students with the requirements for effectively engaging in the workplace, as well as clarifying expectations about the workplace learning environment, e.g. requirements of the position (placement) and organizational norms. Organizational norms will vary across organizations and WPL hosts. Informing students of, or facilitating students to inquire about expectation, purposes, and support structures of the different parties within the organization will help to prepare students for WPL, and help ensure students are set up for more successful interactions while in the WPL environment.

\section{Conclusions and Future Work}

Developing students' capacity to become reflective practitioners, by self-assessing their goal setting abilities and developing approaches to progress towards goal completion, is important 
in helping students maximize learning in their WPL experiences. Co-op and WPL educational models have the capacity to develop and shape students, and future, in their early career experiences. Scaffolding and supporting students early on in these processes can facilitate purposeful engagement throughout their professional practice. Future work related to this study will involve developing quantitative instruments, e.g. surveys, used to assess data that can document students' progression through their placements, and find any common threads across students and placements.

\section{References}

[1] Stevens, R., Johri, A., \& O’Connor, K. (2014). Professional Engineering Work. In A. Johri \& B. Olds (Eds.), Cambridge Handbook of Engineering Education Research (pp. 119-138). Cambridge: Cambridge University Press. doi:10.1017/CBO9781139013451.010

[2] Trede, F., \& Smith, M. (2012). Teaching reflective practice in practice settings: students' perceptions of their clinical educators. Teaching in higher education, 17(5), 615-627.

[3] Hitlin, S., \& Elder, G. H. (2007). Time, self, and the curiously abstract concept of agency. Sociological theory, 25(2), 170-191.

[4] Paretti, M. C., \& Kotys-Schwartz, D. A., \& Howe, S., \& Ford, J. D., \& Lutz, B. D., \& Kochersberger, K., \& Gewirtz, C., \& Rosenbauer, L. M., \& Arunkumar, S. (2017, June), Board \# 116 : Collaborative Research: From School to Work: Understanding the Transition from Capstone Design to Industry Paper presented at 2017 ASEE Annual Conference \& Exposition, Columbus, Ohio. https://peer.asee.org/27700

[5] Reidsema, C., Goldsmith, R., \& Mort, P. (2010, June). Enabling the reflective practitioner in engineering design courses. In 2nd International Conference on Design Education (ConnectED2010). The University of New South Wales.

[6] Trede, F. (2017). Interact2: EEL513 - Workplace learning: Theory and Practice. "WPL Preparation."

[7] Vygotsky, L. S. (1980). Mind in society: The development of higher psychological processes. Harvard university press.

[8] Piaget, J. (2013). The construction of reality in the child (Vol. 82). Routledge.

[9] Lave, J., \& Wenger, E. (1991). Situated learning: Legitimate peripheral participation. Cambridge: Cambridge University Press.

[10] Peach, D., Ruinard, E. \& Webb, F. (2014) Feedback on student performance in the workplace: the role of workplace supervisors. Asia-Pacific Journal of Cooperative Education, Special Issue, 2014, 15(3), 241-252.

[11] Bowen, G.A. (2009) "Document Analysis as a Qualitative Research Method", Qualitative Research Journal, Vol. 9 Issue: 2, pp.27-40, https://doi.org/10.3316/QRJ0902027

[12] Rowe, A., Mackaway, J., \& Winchester-Seeto, T. (2012). 'But I thought you were doing that' Clarifying the role of the host supervisor in experience based learning. Asia-Pacific Journal of Cooperative Education, 13(2), 115-134. 
[13] Billett, S. (2011). Guidelines for practice: integrating practice-based experiences. Retrieved from https://www.academia.edu/16918338/Guidelines for practice Integrating practicebased experiences

[14] Richardson, J., Jackling, B., Kaider, F., Henschke, K., Kelly, M. P., \& Tempone, I. (2009). The role of industry supervisors in providing feedback to students as part of the assessment process in Work Integrated Learning (WIL), ATN Conference Assessment, RMIT University, Melbourne, Australia, 282-292.

[15] Winchester-Seeto, T., Rowe, A. and Mackaway, J. (2016) Sharing the load: Understanding the roles of academics and host supervisors in work-integrated learning. Asia-Pacific Journal of Cooperative Education, 2016, 17(2), 101-118). Retrieved from http://www.apjce.org/files/APJCE 17 2 2 101 118.pdf

[16] Trede, F. (2017). Interact2: EEL513 - Workplace learning: Theory and Practice. "WPL Preparation." 